\title{
Da cópia institucional à vitalidade organizada: o Brasil de Unger
}

\section{Carlos Sávio Teixeira}

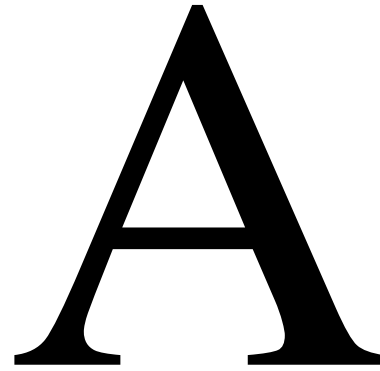

obra de Roberto Mangabeira Unger, teórico brasileiro radicado na Universidade de Harvard, nos EUA, desde o início dos anos 70 , tem sido objeto de reflexões em vários centros acadêmicos internacionais. O intelectual britânico Perry Anderson, por exemplo, fazendo um denso apanhado de suas ideias, e chamando a atenção para sua originalidade, fez a seguinte consideração: "Em termos de ataque imaginativo, o projeto de reconstrução social de Unger não tem correspondente em nossos dias. Com certeza, ele cumpre a promessa de avançar para além, muito além, das ambições da social-democracia" (Anderson, 2002, pp. 188-9). No entanto, quando se consulta as principais publicações acadêmicas em língua portuguesa se constata uma quase total falta de discussão de sua obra. Este artigo tenta contribuir para o suprimento dessa lacuna, em especial no que diz respeito à interpretação desse teórico contemporâneo acerca de seu país natal.

O Brasil representa, para Unger, o mundo em que as questões fundamentais apareceram encarnadas em sua forma mais rica: não apenas como ideias ou doutrinas, mas como encruzilhadas coletivas e individuais. A parte mais importante de seu pensamento, a dedicada à política, está sempre inspirada simultaneamente por uma construção teórica a respeito da sociedade e da história universais e por um confronto com o mundo brasileiro. Em seu pensamento não há uma escolha entre o universal e o local. O local é a manifestação do universal, no sentido de que existe uma cadeia de analogias que ligam o Brasil ao restante do mundo. Tanto a sua interpretação dos constrangimentos brasileiros quanto a sua proposta de reorganização institucional do Brasil é o reflexo dessa dialética. Nesse sentido, é um equívoco enxergar a análise ungeriana do Brasil como a base para uma proposta de um caminho brasileiro no sentido nativista, idiossincrático e específico. O mais adequado é percebê-la como uma direção universal, porém construída no Brasil ${ }^{1}$.

Texto publicado nos Anais do III EICS - Encontro Internacional de Ciências Sociais: Crise e Emergência de Novas Dinâmicas Sociais, Grupo de Trabalho 2. Pensamento Político e Instituições Políticas Latino-americanas, realizado em Pelotas (RS) em 2012, com o título "A Vitalidade Desperdiçada".

1 O filósofo Richard Rorty, em seu ensaio sobre a obra de Unger, defendeu a tese oposta à deste trabalho, argumentando que "sua audiência natural encontre-se no Terceiro Mundo, onde seu livro há de tornar possível algum dia um novo romance nacional" (Rorty, 1999, p. 248). Para o pragmatista norte-americano a atmosfera de desencanto e frustração dominante no Atlântico Norte não comporta um projeto cujo leitmotiv é a invenção institucional dirigida aos campos da economia e da política.

CARLOS SÁVIO TEIXEIRA é professor adjunto de Ciência Política da Universidade Federal Fluminense. 
Alguns estudiosos da obra de Unger chamam a atenção para o fato de ele ser brasileiro e da ligação de sua obra com o Brasil (Anderson, 2002; Cui, 2001; Rorty, 1999; Simon, 1990), embora, talvez, não tenham percebido o quanto a sua obra, ao ser brasileira, é também universal, no sentido da observação weberiana de que as rebeldias espirituais ou intelectuais se afirmam mais facilmente na periferia do que no centro de um grande sistema de poder - mais na Palestina do que em Roma (Weber, 1952). Em parte porque a percepção do mundo, a partir da perspectiva da periferia, ajuda no enfrentamento do centro. Intelectualmente, interpreto a posição de Unger como similar à de Tocqueville, quando ele observou, ainda no século XIX, em A Democracia na América, os traços característicos dos EUA como paradigmáticos e exemplares de tendências gerais da humanidade².

Para Unger o Brasil é um país em que o sincretismo é ao mesmo tempo o problema e a solução: uma enorme vitalidade enfeixada numa camisa de força, com uma constante transposição de categorias para terrenos impróprios, mas sempre ostentando uma realidade que prenuncia um aspecto da vida contemporânea em todo o mundo. Essa visão é muito distinta daquela de pensadores americanos que abordaram os EUA sob o ponto de vista da tese de sua excepcionalidade, cuja ideia básica é que os Estados Unidos encontraram no momento de fundação da república uma fórmula institucional singular e perfeita para combinar com precisão a emancipação individual com a prosperidade material. A perspectiva ungeriana se afasta dessa visão e se aproxima, portanto, da abordagem tocquevilliana, que interpretou a realidade norte-americana como uma prefiguração de uma tendência universal. É nesse sentido que a interpretação de Unger a respeito do Brasil é muito parecida com a do pensador francês.

A tese da excepcionalidade americana teve várias manifestações ao longo da história das ideias. Uma das versões mais ideológicas pode ser encontrada no livro de Seymour Lipset (1996), American Exceptionalism: A Double-Edged Sword. Para Unger o "excepcionalismo americano" tem duas faces: a boa e a ruim. Geralmente os defensores - norte-americanos ou não - dessa tese a identificam com aquilo que Unger considera a parte ruim, a idolatria constitucional, baseada na ideia de que os Estados Unidos desfrutam de uma fórmula institucional perfeita. Enquanto para ele, Unger, ao contrário,
“[...] o experimentalismo é a parte mais defensável do excepcionalismo norte-americano; ainda assim, somente sob a pressão de crise extrema é que os norte-americanos marcaram suas instituições com o impulso experimentalista. Os maiores pensadores americanos foram aqueles que, como Jefferson e Dewey, tentaram persuadir seus contemporâneos a trocar um excepcionalismo norte-americano ruim por um experimentalismo norte-americano bom. Os períodos mais importantes da história norte-americana foram aqueles em que interesses se entrelaçaram a ideais, porque tanto ideais quanto interesses colidiram com estruturas institucionais" (Unger, 2004, p. 45 , grifos meus).

Mas, distintamente de Tocqueville, nostálgico do Ancient Regime e satisfeito com a solução "madisoniana" para os males e perigos republicanos, o experimentalista brasileiro procura pensar a estrutura social e psicológica do país como um entrave para o desenvolvimento de inovações institucionais capazes de instrumentalizar suas potencialidades. Unger começa por refletir a respeito daquilo que é constante no Brasil, segundo a sua visão: a tradição dominante de cópia das instituições dos países que nos acostumamos a tomar como referência. Em sua análise da formação do Brasil contemporâneo, Unger enxerga duas fortes e principais "posições de opinião" que formam os dois grandes "partidos" brasileiros: a do partido da onda e a do partido da mensagem (Unger, 2001, pp. 24-31).

O partido da onda sustenta a ideia de que o Brasil tem de se adaptar de forma subordinada à correlação

\footnotetext{
2 No esforço de explicar a maneira como entende o vínculo entre a vitalidade característica da vida social brasileira e as inovações institucionais que propõe, Unger tem crescentemente comparado o Brasil com os Estados Unidos. Mas, ao contrário do estilo dominante dessas comparações feitas aqui no Brasil - nos EUA ninguém sequer imagina a possibilidade desse exercício -, ele enfatiza traços pouco ou nunca arrolados pelas comparações: primeiro, o fato de serem as duas sociedades mais desiguais em suas estruturas de classes dentre os seus tipos e, segundo, o fato de nessas duas sociedades a maioria das pessoas comuns continuarem alimentando a esperança de que "tudo é possível". São, portanto, semelhanças sociais e morais, obviamente não reconhecidas em nenhum dos dois países, embora por razões distintas. Já na comparação entre as elites desses dois países, Unger enxerga enorme diferença nas suas posturas em relação a quase tudo. Um exemplo é que, segundo ele, enquanto os norte-americanos são obcecados com o futuro nacional, os brasileiros se preocupam mais com o futuro dos EUA (Unger, 2008; 2001a).
} 
de forças que existe no mundo, tal como comandada pelas potências dominantes do momento. Na ótica ungeriana, quase sempre o Brasil foi governado por dirigentes comprometidos com o ideário do partido da onda, desde Campos Salles até Fernando Henrique Cardoso. A formulação intelectual básica do partido da onda é a seguinte: a Inglaterra e os EUA organizam o mundo, e o Brasil assume uma posição dentro do mundo organizado por eles. Mas, para assumir uma posição dentro desse mundo, o país tem de aceitar e se conformar com essa diferença, posta sempre em termos de inferioridade do Brasil.

O outro partido é o da mensagem. Ele geralmente se rebela contra a ideia de o país assumir uma posição subordinada na correlação de força organizada pelas potências dominantes e insiste em estabelecer dentro do país uma forma de vida semelhante àquela que existe nos países centrais. Não basta, de acordo com esse ideário, encaixarmo-nos na estrutura organizada pela Inglaterra ou EUA. Temos que nos tornar mais parecidos com Inglaterra ou EUA. Para Unger, paradoxalmente, o problema do "partido da mensagem" foi sempre a mensagem ou, antes, a "falta" dela. A sua mensagem sempre foi a da cópia ou importação das instituições econômicas e políticas desses países. O problema é que essas instituições, quando transportadas para uma sociedade dividida e extremamente desigual como a brasileira, não conseguem surtir os efeitos que produzem nos lugares de onde as importamos e nem muito menos, portanto, resolver os nossos problemas, pela razão simples de que foram desenhadas para enfrentar outros desafios e problemas. Daí que o eixo central do pensamento ungeriano sobre o Brasil tem sido, desde suas primeiras intervenções, a convicção de que sem a reconstrução do arcabouço institucional do país não se resolvem seus graves problemas.

Essa avaliação da disposição política e mental nacional decorre da interpretação de Unger sobre o "paradoxo" central do Brasil. Para ele um dos atributos mais salientes do país é sua vitalidade. Uma vitalidade que tem manifestações econômicas e culturais. Mas o problema de fundo do país é ter se metido numa espécie de camisa de força de instituições, de práticas e de ideias que suprimem essa vitalidade ao invés de instrumentalizá-la. Embora ele sustente que esse arranjo bloqueador, a despeito da reprodução espetacular da desigualdade e da pobreza que também singularizam o Brasil, não mitigou a imensa energia criativa e empreendedora que surge de baixo para cima em quase todo lugar no país. Essa visão de Unger é informada por uma análise teórico-sociológica da realidade brasileira ${ }^{3}$. Nela sobressai a convicção de que o enigma brasileiro aparece na sua forma mais concentrada na maioria desorganizada, não só dos trabalhadores, mas também de parte da própria classe média. E mais: em sua visão não é possível construir uma solução nacional a partir de uma confederação das minorias organizadas. Para ele um dos grandes problemas político e moral - do país é, de um lado, a divisão entre os corporativismos que sufocam a sociedade e, de outro, a maioria desorganizada que se insurge de forma ad hoc contra essa aliança de lobbies e de interesses sectários ${ }^{4}$.

A obra de Unger especificamente dedicada ao Brasil se organiza em torno de dois grandes eixos. De um lado, uma preocupação substantiva e, de outro, uma ambição metodológica. A primeira oferece uma visão abrangente acerca do país, ancorada em ideias formuladas por sua teoria social. A segunda procura construir uma maneira de pensar e propor programaticamente. Essas incursões analíticas no universo brasileiro compreendem o período que vai da fase terminal do regime militar até hoje. Ao longo desse tempo a trajetória de seus escritos evidencia tanto o amadureci-

3 A produção bibliográfica de Unger sobre o Brasil compõe-se de inúmeros artigos e entrevistas apresentados na imprensa e de quatro livros publicados que procuram dar conta, em momentos específicos da vida nacional, de sua compreensão dos limites e das oportunidades do país. Os livros sobre o Brasil são os seguintes: o primeiro, sob o título Participação, Salário e Voto. Um Projeto de Democracia para o Brasil, foi escrito conjuntamente com o economista Edmar Bacha em 1978; o segundo, publicado em 1990, chama-se A Alternativa Transformadora: Como Democratizar o Brasil; o terceiro, resultado de sua parceria política com Ciro Gomes, intitulado O Próximo Passo - Uma Alternativa Prática ao Neoliberalismo, data de 1996; o quarto e último até agora denomina-se A Segunda Via: Presente e Futuro do Brasil, lançado em 2001. Em 1998, Unger iniciou contribuição regular ao jornal Folha de S. Paulo, onde manteve uma coluna semanal até a sua entrada como ministro no governo Lula, em junho de 2007.

4 Essa visão a respeito do Brasil explica muito das opções políticas concretas de Unger: por que, por exemplo, ele sempre rejeitou partidos e movimentos que se apresentavam como porta-vozes das minorias organizadas e que, ao mesmo tempo, imaginavam essas minorias organizadas como os representantes virtuais da maioria silenciada. Na verdade ele jamais se seduziu pela ideia de que o agente da transformação fossem os setores organizados, supostamente formadores da base de uma esfera pública não estatal que, finalmente, energizaria nossa incipiente cidadania (Unger, 1990, pp. 53-62). 
mento da preocupação substantiva, como a redefinição da prática metodológica. Cada vez menos os seus textos contendo as análises e as propostas programáticas brasileiras tomam a forma de um receituário fechado. Ao contrário, eles passam a indicar a demarcação de uma direção, apresentada em inúmeros exemplos de possíveis iniciativas 5 .

A reflexão sociológica sobre a sociedade brasileira tem apresentado quadros interpretativos que se fundamentam em matrizes teóricas variadas. Há, por exemplo, análises sob inspiração marxista, funcionalista, weberiana, estruturalista, entre outras mais. Porém, do ponto de vista da ressonância política das interpretações do Brasil pelos nossos estudos sociais, as duas vertentes mais influentes são o culturalismo sob influência das ciências sociais de cepa norte-americana, como, por exemplo, a teoria da modernização, e o marxismo de origem europeia. São elas que, de uma maneira geral, informam o debate sobre as possibilidades futuras da nação. $\mathrm{O}$ tipo de análise preconizada pelo pensamento de Unger diverge dessas duas tradições. Para ele, essas formas de análises sociais, aparentemente contraditórias, quando tratam de explicar o país, concordam no essencial: "Advogam em favor do destino. Geram narrativas fantasmagóricas que apresentam as atribulações do Brasil ora como o preço da convergência ao caminho único dos países ricos, ora como fardo que a história ou o capital obriga países atrasados a carregar" (Unger, 2001, p. 101). Para se compreender o significado político da diferença entre esses estilos de reflexão e o postulado por Unger, tome-se o exemplo da questão referente aos desdobramentos nacionais de uma proposta de mudança institucional.

Para essas duas vertentes teóricas dominantes parece fundamental basear as análises dos problemas e das oportunidades da realidade nacional fundamentando a percepção a partir de considerações sobre a divisão das relações internacionais entre os países centrais e os periféricos. As questões nacionais seriam delimitadas pelas questões internacionais ${ }^{6}$. Na compreensão de Unger, a definição dessa circunstância nesses termos é apenas mais uma expressão daquilo que considera o fatalismo histórico dominante nas correntes clássicas do pensamento social: "cercear a imaginação do possível sob o pretexto de explicar o surgimento do existente" (Unger, 2001, p. 35). Nessa questão da relação centro e periferia, por exemplo, a sua ideia básica é que a história não é uma máquina que reproduza de forma permanente relações de centro e periferia: os países que agora são predominantes, sobretudo os Estados Unidos, se tornaram predominantes porque combinaram uma fórmula institucional exitosa com um projeto ideológico sedutor para a maior parte da humanidade. Não há nenhuma justificativa intelectual ou científica que autorize a ideia de que os poderes econômicos e militares propiciados por essa fórmula e sua sedução ideológica não possam ser desgarrados da sua base e reinventados em outro registro e contexto ${ }^{7}$.

5 Muito importante a se observar é o fato de as obras de Unger sobre o Brasil não contemplarem análises sobre a formação histórico-social ou cultural do país. Como indica o subtítulo de seu último livro, Presente e Futuro do Brasil, as grandes reconstruções genealógicas, típicas de nossa tradição intelectual, não o atraem. Para uma compreensão das possíveis razões para essa opção teórica, ver outro trabalho em que discuto as linhas gerais de seu pensamento (Teixeira, 2011).

6 Para se ter uma ideia de como é arraigada entre nós a visão que compreende o problema da relação internacional a partir da ideia de que a periferia do "sistema" está impossibilitada de ter sucesso em qualquer tentativa de estratégia de desenvolvimento fora do controle gravitacional do centro, para o bem ou para o mal, tome-se o seguinte exemplo: no livro Conversas com Economistas Brasileiros II, os seus organizadores propõem aos entrevistados a seguinte questão: "Recentemente, o filósofo Mangabeira Unger disse que a teoria da dependência não rompeu com as velhas teses reformistas do PCB, mas foi uma espécie de justificativa para a adesão ao status quo. Alguns intelectuais brasileiros teriam jogado fora as aspirações transformadoras do marxismo e conformaram-se com a dependência do país. A análise sociológica de inspiração marxista praticada por FHC teria servido para provar que não há outro caminho senão a integração subordinada ao capitalismo internacional. Você concorda com isso?". A obra é composta por doze entrevistas com renomados economistas. Somente a dois entrevistados não foi dirigida a questão. Seis disseram que não concordavam. E os outros concordavam parcialmente. $\mathrm{O}$ curioso é que muitos dos que discordaram foram críticos veementes da orientação do governo FHC. Ver Mantega e Rego (1999).

7 Em suas formulações sobre a questão, Unger tem procurado operar analiticamente em dois planos simultâneos: "rebelião nacional e organização internacional". De um lado, propõe formas alternativas de "globalização" - a reorientação do regime internacional do comércio, a reorganização das instituições multilaterais do sistema Bretton Woods e um conjunto de entendimentos entre as potências médias (China, Rússia, Índia e Brasil) que permitiriam, pouco a pouco, transformar a natureza da hegemonia americana. Tudo isso para criar uma forma de globalização mais propícia ao "pluralismo". De outro lado, sustenta que a energia para lutar por essa reconstrução do regime global tem de vir da tentativa de reorientar os projetos nacionais: somente quando se tenta desenvolver um projeto nacional alternativo ao limitado pela forma atual de globalização, torna-se possível levar adiante essa ideia de mudar as regras da globalização (Unger, 1999, pp. 73-6). 
Para Unger, à medida que outros países começarem a descobrir a maneira de fortalecer aquelas vantagens materiais e morais por outros caminhos, os centros "imperiais" serão fragilizados e progressivamente constrangidos. A sua tese básica é que a luta sobre a relação centro e periferia está aberta e que o decisivo nela é o conteúdo substantivo das ideias. A tradução dessa questão nos termos específicos da situação contemporânea não é difícil de imaginar: a estrutura da forma atual de globalização, apesar de impor dificuldades às tentativas de criação de alternativas nacionais, não impõe constrangimentos a ponto de impedir que as alternativas venham à tona. Afinal, mesmo dentro da estrutura atual das relações internacionais, países como a China surgem e crescem representando modelos diferentes de organização da produção, da política e de relacionamento entre o centro e a periferia ${ }^{8}$.

Mas, numa perspectiva como a defendida por Unger, a análise do conteúdo institucional alternativo deve ser feita à base de realidade nacional distinta que, sem desconsiderar os constrangimentos externos, se concentre também sobre as oportunidades internas. Para levar a cabo esse estilo de reflexão, o foco tem de se voltar para os problemas estruturais nacionais. No caso específico da situação brasileira, o ponto fundamental é a grande divisão econômica e social que se perpetua. Na visão de Unger, o dualismo econômico é uma forma de divisão profunda do país em dois mundos distintos, porém perfeitamente integrados 9 . Por isso, "os adjetivos 'moderno' e 'tradicional' não traduzem a gravidade dessa separação entre dois mundos sociais. Dão a falsa impressão de que se trata de dois setores situados numa linha evolutiva quando, na verdade, coexistem e se perpetuam reciprocamente" (Unger, 1990, p. 348).

De um lado, está o setor que tem acesso a capital, tecnologia, conhecimento, capacitação. Liga-se ao Estado e dele recebe recursos. Nele se situa e nutre a minoria dos brasileiros. Ele se acha, sem sê-lo, a "locomotiva” do país. Do outro lado, está a parte que ou não tem ou tem precariamente acesso aos bens e direitos usufruídos pelo outro setor organizado e politicamente articulado. A maioria dos brasileiros vive nessa parte do país. Por isso "à divisão social e econômica se sobrepõem divisões raciais e regionais que multiplicam a distância entre os dois mundos" (Unger, 1990, p. 349).

Uma das consequências econômicas desse dualismo é o aprofundamento crescente da distância entre as duas partes. Socialmente, essa situação engendra uma ação do Estado que, "por um paradoxo que não se tem devidamente apreciado, o dualismo deixa suas marcas na própria estrutura assistencialista: muitos dos nossos programas de previdência social e ajuda médica divide-se entre os que se dirigem aos trabalhadores do setor moderno, e os que sobram para os outros" (Unger, 1990, p. 350). E o que torna a situação ainda mais dramática, na visão de Unger, é que "tragicamente para o país, as principais doutrinas progressistas desenvolvidas ou adotadas no Brasil tomaram o dualismo por dado, quando não contribuíram para fortalecê-lo" (Unger, 1990, p. 350). Esse foi o caso das interpretações marxistas ortodoxas e do programa histórico do Partido dos Trabalhadores (Unger, 1994).

Por outro lado, as propostas de reorganização institucional do país defendidas por Unger também se afastam de muitos dos principais projetos de moder-

8 Para uma discussão teórica das teses de Unger sobre a economia internacional no atual período de globalização, ver o seu livro intitulado A Reinvenção do Livre-Comércio: A Divisão do Trabalho no Mundo e o Método da Economia, em que sustenta ser altamente nociva a evolução do regime internacional do comércio, sob a OMC, que caminha no sentido de um maximalismo institucional: a tendência de impor aos países comerciantes em nome do livre-comércio não apenas o compromisso com a economia de mercado, mas o compromisso com um tipo particular de economia de mercado. É um exemplo disso a proibição, sob o rótulo de subsídios, de todas as formas de coordenação estratégica entre governos e empresas que os países hoje ricos usaram, com a única possível exceção da Grã-Bretanha, em suas estratégias de enriquecimento. O interesse de um país como o Brasil é substituir o maximalismo institucional por um minimalismo institucional em matéria de regime de comércio. $O$ máximo de abertura econômica com o mínimo de regras restritivas. Esse é um exemplo do interesse maior em construir uma ordem econômica internacional mais propícia ao pluralismo de poder e de visão do que ela ostenta hoje (Unger, 2010).

9 Nesse sentido é possível imaginar a concordância de Unger com as críticas à centralidade que o tema da herança ibérica e suas consequências como o personalismo ocupa em nosso atual debate. Para o filósofo brasileiro, o desafio político central do Brasil contemporâneo não é o "jeitinho brasileiro" ou a nossa suposta corrupção endêmica - que pressupõe uma sociedade com fortes vínculos pré-modernos baseada em relações pessoais, cuja contrapartida institucional é o patrimonialismo -, mas a construção de ordem institucional capaz de enfrentar problemas como a nossa abissal desigualdade social, naturalizada pelas explicações baseadas na ideia de um passivo histórico negativo ou nas consequências impeditivas de desenvolvimento para países periféricos próprias ao capitalismo. Para Unger, as condições para o enfrentamento de nossos principais problemas estruturais não só estão à mão, como podem ter rápido efeito (Unger, 2001). 
nização formulados pelo pensamento político e estratégico brasileiro. Um dos temas principais de nosso pensamento político foi a construção do projeto de um Estado nacional. Na maioria das vezes a formulação dessa ideia se fez acompanhar da ausência de uma visão política e econômica compatível com a defesa da democracia no plano da organização da sociedade e na esfera da estratégia econômica: quase sempre esteve eivada de uma perspectiva fundada no autoritarismo e no dirigismo tecnocrático. Essas tendências foram inspiradas pelo positivismo reinante no século XIX e deixaram o seu legado no século XX. A ideia básica do projeto supõe uma vanguarda esclarecida que constrói o Estado forte e usa esse Estado para definir uma trajetória independente do país ${ }^{10}$.

As ideias políticas de Unger já foram frequentemente confundidas com uma concepção similar à do nosso construtivismo. Mas suas concepções parecem passar muito longe da tentativa de construção de um aparato estatal forte sob o controle de uma elite esclarecida. A ideia central de sua visão está na dialética entre a construção de uma forma de vida política e econômica que tem como tarefa principal generalizar e acelerar a inovação - transformar o poder imaginativo no mecanismo central da sociedade - e na criação de um indivíduo - cidadão e trabalhador - capaz de engrandecer-se. Portanto, experimentalismo e engrandecimento são os dois slogans de suas propostas sociais e políticas, o que o coloca em campo antagônico ao dessa tradição autoritária de nosso pensamento político. Da mesma forma que o distancia das formulações de nosso liberalismo, na maioria das vezes, conservador ${ }^{11}$.

Além da ideia central de reconstrução institucional do mercado e da democracia, o pensamento programático de Unger evoluiu progressivamente rumo à concepção de outras três grandes áreas onde se desdobra sua concepção analítica principal. A primeira delas ocupa o seu pensamento a respeito do Brasil há muito tempo, qual seja, a capacitação da enorme população desprovida de capital cultural, tendo em vista, sobretudo, duas prioridades: a primeira é assegurar dentro de um país muito grande, muito desigual e de regime federativo a reconciliação da gestão local dos sistemas escolares pelos estados e municípios, como prevê a nossa atual Constituição, com padrões nacionais de investimento e de qualidade. E a segunda é a insistência em transformar o modo de ensinar: substituir o modelo pedagógico enciclopédico e superficial por um ensino analítico que utilize a informação de maneira seletiva e aprofundada. Na verdade, essa sua proposta significa antecipar para as primeiras etapas do ensino o trabalho cooperativo que caracteriza os estágios mais avançados da ciência, acabando assim com a coexistência de certo predomínio de individualismo e de autoritarismo nas nossas salas de aula, além de insistir na ideia de que os assuntos devem ser abordados de maneira dialética por um contraste de pontos de vista: toda matéria deve ser ensinada pelo menos duas vezes, a partir de visões conflitantes ${ }^{12}$.

O segundo eixo analítico de seu desdobramento programático surge no contexto da discussão que se tornou conhecida no Brasil como a "porta de saída" dos programas de transferência de renda, comumente

$10 \mathrm{Na}$ verdade há todo um conjunto de intelectuais que defenderam essa vertente, como Francisco Campos, "o ideólogo do Estado Novo", Oliveira Viana, Alberto Torres e, principalmente, Azevedo Amaral - o mais direto e impetuoso teórico de nosso construtivismo modernizador. O título de sua principal obra permite que se perceba, sem rodeios, o drama da questão: O Estado Autoritário e a Realidade Nacional. Há, entretanto, no âmbito do pensamento político brasileiro, outra grande vertente inspirada na doutrina liberal. Entre outros, seriam representativos dela autores como Tavares Bastos, Rui Barbosa, Sérgio Buarque de Holanda e Raymundo Faoro. Embora não deva haver dúvidas de que a não adesão de Unger ao ideário autoritário de nosso construtivismo também não signifique concordância com o nosso liberalismo, marcado segundo ele pela excessiva falta de imaginação e convencionalismo, incapazes de enfrentar os reais desafios do país.

11 O economista Luís Gonzaga Belluzzo, comentando em artigo de jornal uma entrevista de Unger concedida em 1997, captou precisamente a confusão - e o seu uso político - acerca das ideias de Unger sobre o Estado. Ele cita uma passagem da entrevista em que se lê uma crítica de Unger à ideologia de auto-organização da sociedade civil, segundo a qual "a sociedade faz, o Estado não. É um ideário que justifica esse amesquinhamento da política e o combate às ideias de alternativas institucionais". Diante dessa crítica firme de Unger, Belluzzo concluiu sarcasticamente: "O tucanato social-democrata e seus acólitos parecem reagir a esse diagnóstico, carregado imaginam eles de populismo implícito, com a mesma náusea imagino eu que afligia os senhores de escravos diante da presença da senzala" (Belluzzo, 1997).

12 A crença no poder social da educação evidenciada por grandes pensadores liberais como John Dewey e Bertrand Russell é fortemente compartilhada por Unger. Um dos temas caros ao seu pensamento programático é aquele referente às ideias sobre uma forma de ensino que, no espírito de Platão, resgate a criança das limitações de seu meio - de sua família, de sua classe, de seu tempo histórico, de sua cultura nacional - e lhe dê os instrumentos da resistência e da antevisão (Unger, 1999, pp. 180-5). No panorama da educação brasileira a identificação de Unger é com a perspectiva pedagógica de Anísio Teixeira, que, além de discípulo do experimentalismo de Dewey, como Unger, foi secretário de educação do estado da Bahia na época em que Otávio Mangabeira, avô de Unger, foi governador. 


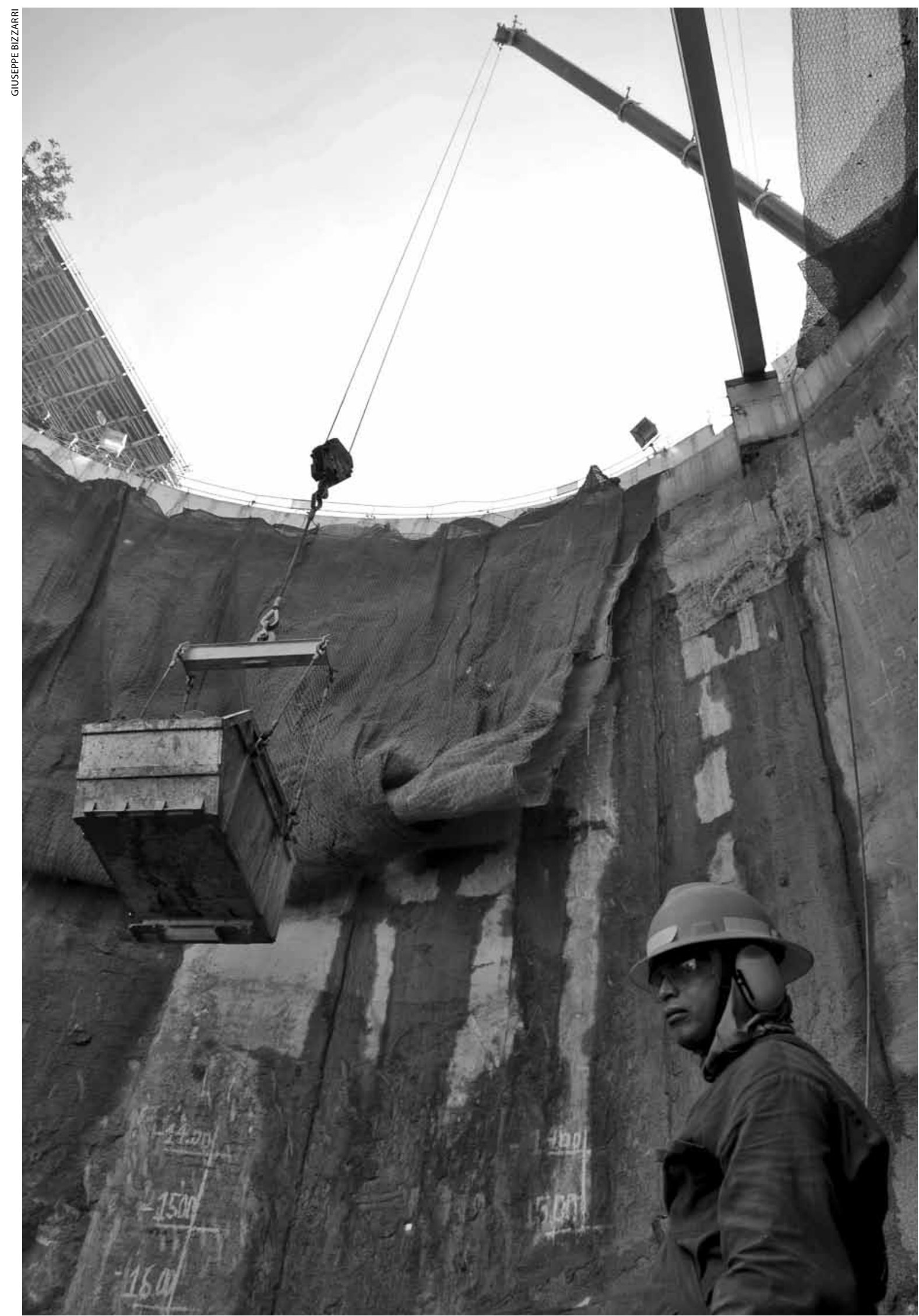

Vista de obras para construção de túnel na praça Mauá, no Rio de Janeiro 
proposta pelos representantes intelectuais e políticos da direita. A ideia básica é a que os programas de transferência são resgates de cidadania, já que na miséria as pessoas são imobilizadas, inclusive pelo medo. Dessa forma os programas de transferência devem ser entendidos como instrumentos que criam as condições para uma mobilização mínima (Vanderbought \& Parijs, 2006). O que Unger diz em resposta é que as transferências representam uma condição necessária, mas muito insuficiente, para enfrentar uma desigualdade social como a brasileira. E que, portanto, deveria haver uma versão progressista - que não há - dessa discussão sobre as "portas de saída", descritas por outra linguagem que enfatizasse a necessidade de agregar elementos de ampliação da oportunidade e de capacitação a esses programas.

A ideia se baseia num dado empírico sobre a atual estrutura de classes no Brasil e sobre o perfil dos beneficiários dos programas de transferência como o Bolsa Família. Quando se observam os dados recentes a respeito da evolução da renda e de seus componentes no Brasil, verifica-se o seguinte: embaixo, entre aqueles descritos por Souza (2009) como a "ralé" brasileira, houve um crescimento da renda, sem que tenha havido um crescimento da renda do trabalho. Entende-se que a maior parte desse crescimento se deve aos programas de transferência de renda. Mais adiante, no gráfico de evolução da renda, houve um crescimento menor, mas uma proporção muito maior desse crescimento devido à renda do trabalho. E a partir daí a curva continua a descender (Paes de Barros, 2008).

Essa constatação empírica inspirou uma conjectura causal: entre o núcleo duro da pobreza, de um lado, e a pequena burguesia empreendedora, de outro, haveria um grupo intermediário, que Unger passou a chamar de "batalhadores". Esse grupo social seria composto basicamente por pessoas que surgem mais ou menos no mesmo meio pobre da "ralé", do núcleo da pobreza, mas que por razões sociológicas especiais responderam às duríssimas circunstâncias coletivas às quais estão submetidas e conseguiram iniciar seu autorresgate - e muito importante é o fato de que essas pessoas existem aos milhões no Brasil. Essa hipótese a respeito da estrutura de classes inspirou em Unger uma sugestão programática: o desdobramento capacitador dos programas de transferência teria de ter em vista essa diferença entre a "ralé" e esse grupo chamado de "batalhadores". O núcleo duro de miseráveis é composto por pessoas que estão cercadas por um conjunto de inibições familiares e culturais que dificulta a eficácia dos programas de capacitação. A experiência mundial de programas de capacitação dirigidos a esse núcleo duro da miséria é desalentadora (Galasso, 2006).

Mas o malogro se explicaria por causa desse conjunto de inibições sociais e culturais. Para a "ralé", portanto, não funcionaria uma iniciativa direta de capacitação. A primeira coisa a fazer é assegurar que o Estado consiga assumir algumas das funções das famílias desestruturadas e adensar o sistema de assistência social. Isso não objetiva substituir a família, mas complementá-la. Já os "batalhadores" seriam os alvos naturais dos programas de capacitação, na medida em que já demonstraram que são resgatáveis, por uma razão simples: de alguma maneira já iniciaram o seu próprio resgate. De acordo com a conjectura ungeriana o equívoco comum que se comete no mundo é dirigir os programas de capacitação aos mais pobres. Embora seja compreensível pensar que a capacitação deva começar pelos mais carentes, a lógica da política não deve ser a mesma da caridade. Então, paradoxalmente, os programas de capacitação teriam que começar não pelos mais pobres, mas pelos relativamente menos pobres, que funcionariam como uma espécie de "vanguarda" da massa mais carente que viria em seguida ${ }^{13}$.

Para Unger, há no Brasil uma divisão entre os que dizem que se pode apenas "humanizar" as estruturas existentes, e os que querem inovar, transformando as estruturas. O primeiro programa defende a ação do Estado para facilitar a integração das vanguardas produtivas na rede internacional de vanguardas, enquanto espera ajudar o restante que fica excluído a esperar a sua lenta incorporação. Tudo isso acompanhado por uma democracia de baixa energia em que as pessoas procurem os seus interesses privados e tratem a política como uma sequência de episódios desconectados do mundo prático onde operam. E po-

13 Unger escreveu o prefácio do livro Os Batalhadores Brasileiros - Nova Classe Média ou Nova Classe Trabalhadora?, escrito por Souza (2010), que é o resultado de uma pesquisa teórica e empírica abrangente realizada em todas as regiões do Brasil sobre o perfil sociológico dos principais tipos de empreendedores e trabalhadores que integram o grupo social que se tornou suporte das transformações do capitalismo brasileiro nas últimas décadas.

Eles seriam o agente em que Unger deposita suas maiores esperanças e que deveria ser - e ainda não é o principal destinatário das políticas do Estado brasileiro. 
lítica social compensatória para os marginalizados. A alternativa proposta por ele a essa visão seria uma tentativa de aprofundar a democracia e democratizar a economia de mercado por um conjunto cumulativo de inovações institucionais, com o objetivo de implantar no Brasil uma democracia de alta energia e um projeto econômico antidualista, que enfrentasse a divisão das vanguardas e retaguardas.

Concluo com uma observação sobre a visão de Unger a respeito do fenômeno da desorganização na sociedade brasileira. Ela encerra uma polêmica com o pensamento político e sociológico convencionais: para os seus representantes o processo de organização ocorre como uma espécie de universalização das organizações existentes. Por exemplo: a maioria não está efetivamente sindicalizada, então a tarefa é sindicalizá-los. Mesmo quando as organizações sindicais tradicionais estão definhando, a proposta convencional não se altera, nem mesmo taticamente. Então o problema que se coloca para Unger é que, ao invés de denunciar e protestar contra as mudanças vistas como negativas, tem-se de procurar construir uma estrutura econômica, social e política que não apenas amplie horizontalmente a lógica das organizações existentes, mas construa uma nova forma de organização. Afinal, é impossível imaginar o futuro de um país com as características do Brasil como uma espécie de super CUT (Central Única dos Trabalhadores).

A organização futura da economia de mercado e da democracia política não deverá ser a universalização dos interesses de minorias organizadas: poderá ser, ao contrário, uma tentativa de organizar a vida social de modo a quebrar a espinha dorsal dos lobbies e permitir uma nova forma de associação que diminua a tensão entre a necessidade de cooperar e a necessidade de inovar. Formas de organizar a cooperação que sejam mais propícias à inovação do que as formas que existem hoje. Provavelmente, os tipos de organização serão diferentes, e as alternativas institucionais econômicas e políticas propostas por Unger se destinam entre outras coisas a romper a escolha binária entre as formas atuais de organização e a categoria residual do desorganizado: destinam-se a institucionalizar a vitalidade brasileira.

\section{BIBLIOGRAFIA}

ANDERSON, Perry. "Unger e a Política do Engrandecimento", in P. Anderson, Afinidades Seletivas. São Paulo, Boitempo, 2002.

BELLUZZO, Luis Gonzaga. "Democratas e Populistas", in Folha de S. Paulo, 5/10/1997.

CUI, Zhiyuan. "Prefácio", in R. M. Unger. Política. São Paulo, Boitempo, 2001.

GALASSO, Emanuela. "'With their Effort and One Opportunity': Alleviating Extreme Poverty in Chile", The World Bank Development Research Group. 2006. Disponível em: http://www.iadb. org/WMSFiles/products/research/files/pubS-001.pdf.

LIPSET, Seymour Martin. American Exceptionalism: A Double-Edged Sword. New York, W.W. Norton \& Company, 1996.

MANTEGA, Guido; REGO, José Márcio (orgs.). Conversas com Economistas Brasileiros II. São Paulo, Editora 34, 1999.

RORTY, Richard. "Unger, Castoriadis e o Romance de um Futuro Nacional”, in Escritos Filosóficos.

Vol. 2. Rio de Janeiro, Relume Dumará, 1999.

SIMON, William. "Social Theory and Political Practice: Unger's Brazilian Journalism", in Robert Lovin, Michael Perry (orgs.). Critique and Construction - a Symposium on Roberto Unger's Politics. Cambridge, Cambridge University Press, 1990.

SOUZA, Jessé. A Ralé Brasileira: Quem É e como Vive. Belo Horizonte, Ed. da UFMG, 2009. . Os Batalhadores Brasileiros. Belo Horizonte, Ed. da UFMG, 2010. 
TEIXEIRA, Carlos Sávio. “Uma Filosofia Política para a Transformação”, in Revista Estudos Políticos, n. 3, vol. 2. Rio de Janeiro, 2011.

UNGER, Roberto Mangabeira. A Alternativa Transformadora. Como Democratizar o Brasil. Rio de Janeiro, Guanabara, 1990.

"3 de Outubro e o Futuro do PT", in Revista Teoria e Debate. São Paulo, 1994. Democracia Realizada. A Alternativa Progressista. São Paulo, Boitempo, 1999. A Segunda Via: Presente e Futuro do Brasil. São Paulo, Boitempo, 2001.

"Adeus a Godot", in Folha de S. Paulo, 18/9/2001a.

O Direito e o Futuro da Democracia. São Paulo, Boitempo, 2004.

"O Brasil e os Estados Unidos", in Folha de S. Paulo, 4/11/2008.

A Reinvenção do Livre-comércio. Rio de Janeiro, Ed. da FGV, 2010.

UNGER, Roberto Mangabeira \& GOMES, Ciro. O Próximo Passo: Uma Alternativa Prática ao Neoliberalismo. Rio de Janeiro, Topbooks, 1996.

UNGER, Roberto Mangabeira \& BACHA, Edmar. Participação, Salário e Voto. Um Projeto de Democracia para o Brasil. Rio de Janeiro, Paz e Terra, 1978.

VANDERBOUGHT, Yannick; PARIJS, Philippe. Renda de Cidadania: Argumentos Éticos e Econômicos.

Rio de Janeiro, Civilização Brasileira, 2006.

WEBER, Max. Ancient Judaism. New York, Free Press, 1952. 


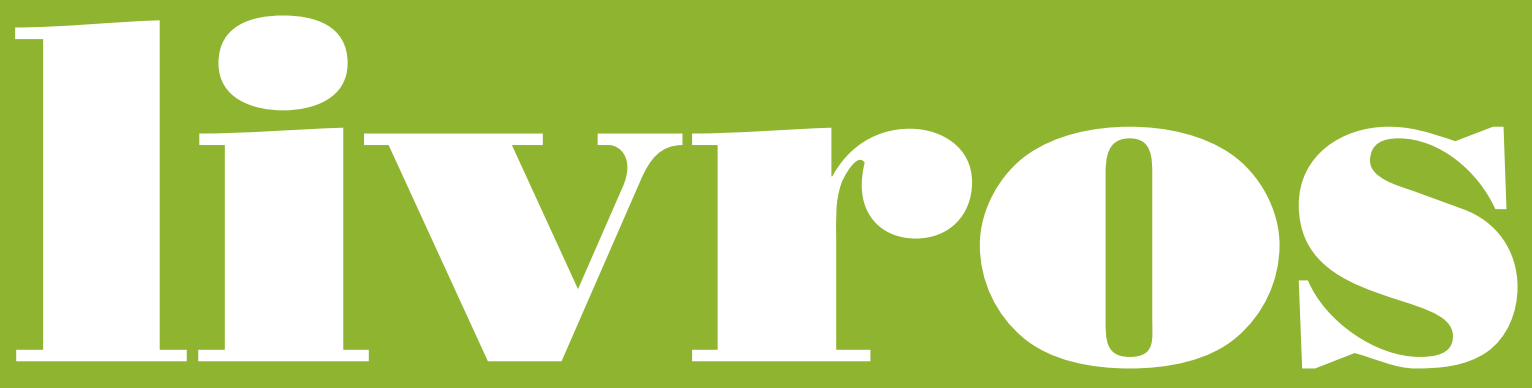

